\title{
The value of haematological screening for AIDS in an at risk population
}

\author{
J N WEBER,* D WALKER,* H ENGELKINS,* B BAIN, † AND J R W HARRIS* \\ From the *Praed Street Clinic and the †Department of Haematology, St Mary's Hospital and Medical \\ School, Paddington, London
}

SUMMARY The haematological variables measured by automated full blood count in matched homosexual and heterosexual men attending a clinic for sexually transmitted diseases (STD) were compared with those of normal controls and patients infected with the human $\mathrm{T}$ lymphotropic virus type III (HTLV-III). Homosexual and heterosexual men were statistically identical for all variables, but both differed noticeably from patients with clinical diagnoses of the acquired immune deficiency syndrome (AIDS) or AIDS related disease. A full blood count as a screening test for AIDS is only interpretable in the context of clinical assessment.

\section{Introduction}

The association of the acquired immune deficiency syndrome (AIDS) with a decrease in circulating peripheral blood lymphocytes is well documented. ${ }^{1-4}$ Absolute lymphopenia preceding opportunist infection and, less commonly, preceding the development of Kaposi's sarcoma, has been shown in patients with AIDS seen at this hospital..$^{5}$ The lymphopenia is characterised by a specific decrease in cells of the T helper phenotype. ${ }^{6}$ The immunological abnormality of isolated $T$ helper depletion is, however, not specific to AIDS, and this lack of specificity, combined with the expense of the test, has limited the clinical applications of screening large populations by this method.

Screening populations at risk of contracting AIDS has now evolved in the major sexually transmitted disease (STD) clinics, and the differential leucocyte count is used increasingly to identify patients with lymphopenia. To define the value of a full blood count with differential as a screening test for AIDS, we undertook a prospective study of haematological variables in attenders at an STD clinic. It was first necessary, however, to know the pattern of haematological variables in homosexual and heterosexual clinic attenders, in whom intercurrent infection with STD may alter the pattern of the "normal" distribution of variables in the full blood count.

Address for reprints: $\mathrm{Dr} J$ Weber, Jefferiss Research Wing, The Praed Street Clinic, St Mary's Hospital, London W2 1NY

Accepted for publication 20 February 1985

\section{Patients and methods}

Men attending the STD clinic at this hospital from 5 March to 9 April 1984, who were venesected for treponemal serology tests, had an additional $4 \mathrm{ml}$ blood taken in K2 tubes containing EDTA (ethylenediamenetetra-acetic acid) for haematological investigations. All patients were fully examined, and an appropriate history was taken.

The following groups of men formed the study population:

(1) asymptomatic homosexual or bisexual men (who had no evidence of generalised lymphadenopathy or any symptoms or signs indicative of AIDS in a prodromal stage, such as symptoms of severe malaise, night sweats, fevers, weight loss, or persistent diarrhoea, or signs of suspicious skin lesions, or oral candidiasis);

(2) asymptomatic heterosexual men (selected on the same criteria as the asymptomatic homosexuals);

(3) healthy male volunteers working in the hospital laboratories or undergoing pre-employment health screening, who were studied as a second control group;

(4) men with persistent generalised lymphadenopathy (PGL) (palpable lymph nodes larger than $1 \mathrm{~cm}$ in diameter at more than one extrainguinal site for more than three months with no identifiable cause of lymphadenopathy) ${ }^{7}$; and

(5) men with AIDS who fulfilled the epidemiological definition of Kaposi's sarcoma or opportunist infection and had no preceding cause of immunosuppression). ${ }^{8}$ Table I shows the composition of these five groups of men. 
TABLE I Composition of five groups of 514 men

\begin{tabular}{lccc}
\hline Group & Number & $\begin{array}{l}\text { Homo- } \\
\text { sexual }\end{array}$ & Bisexual \\
\hline 1 Homosexuals or & & & \\
$\quad$ bisexuals & 168 & 144 & 24 \\
2 Heterosexuals & 219 & 0 & 0 \\
3 Healthy male volunteers & 74 & Not known & Not known \\
4 Patients with PGL & 41 & 39 & 2 \\
5 Patients with AIDS & 12 & 11 & 1 \\
\hline
\end{tabular}

PGL $=$ persistent generalised lymphadenopathy.

AIDS $=$ the acquired immune deficiency syndrome.

The blood was analysed within six hours of venesection using a coulter counter, model S Plus IV, standardised with a $4 \mathrm{C}$ cell control. The following values were measured or calculated: white blood cell count, red blood cell count, haemoglobin concentration, platelet count, granulocyte count, and lymphocyte count. We disregarded platelet counts if platelet aggregation was seen on the blood film. We examined May-Grunwald-Giemsa stained blood films from all subjects, and lymphocyte morphology was categorised as normal, mildly abnormal, moderately abnormal, and strongly abnormal.

We performed 500 cell differential white cell counts on blood from 50 homosexual or bisexual men, 50 heterosexual men, 50 healthy male volunteers, all 41 men with PGL, and all 12 men with AIDS. BB performed all haematological assessments without knowing the subject's study group.

Using the five groups, analysis of variance was performed with and without age as a covariant. Two tailed Student's $t$ testing at the $1 \%$ level was used to assess the significance of differences between the means of the study groups for each of the variables measured.

\section{Results}

Table II lists the mean values and standard deviations for all variables in the five groups. These data are represented graphically in fig 1 . Significant differences at the $0.1 \%$ level by two tailed Student's $t$ test are indicated on the figures by an asterisk. Analysis of variance was performed with and without age as a covariant, and no significant difference was found. Age was therefore discarded as a covariant.

No significant difference was seen between the homosexual or bisexual men (group 1) and the control group of healthy volunteers (group 3). The heterosexual patients (group 2) had a higher red cell count than both the homosexual group and the healthy volunteers.

When compared with the patients with PGL (group 4), both homosexual and heterosexual clinic attenders had higher haemoglobin concentrations and counts of white blood cells, platelets, granulocytes, and lymphocytes, which were significant at the $0.1 \%$ level by the two tailed Student's $t$ test. The patients with AIDS (group 5) differed from the homosexual and heterosexual groups in a similar way, and also differed from the healthy volunteers (group 3).

Comparison between patients with PGL and AIDS showed that patients with PGL had higher haemoglobin concentrations and counts of red blood cells, lymphocytes, and granulocytes, and the difference was significant at the $0 \cdot 1 \%$ level by the two tailed Student's $t$ test.

Atypical lymphocytes were not found more commonly in the homosexual patients than in the heterosexual patients, and were not seen at all in the healthy volunteers (table III).

The average lymphocyte counts by machine and hand did not differ significantly between the homosexual and the heterosexual groups. There was no difference in the standard deviation for lymphocyte counts between these two groups, and the plot diagram (fig 2) showed no difference in distribution between these groups and the healthy volunteers. There was therefore no excess incidence of lymphopenia in a group of asymptomatic homosexuals.

Examination of manual differential counts of 50 randomly selected samples from each of the first three groups and from all of groups 4 and 5 facilitated direct comparison of all cell types. The TABLE II Mean (SD) haematological variables in five groups of men

\begin{tabular}{|c|c|c|c|c|c|}
\hline & $\begin{array}{l}\text { Group } 1 \\
(n=168)\end{array}$ & $\begin{array}{l}\text { Group 2 } \\
(n=219)\end{array}$ & $\begin{array}{l}\text { Group 3 } \\
(n=74)\end{array}$ & $\begin{array}{l}\text { Group } 4 \\
(n=41)\end{array}$ & $\begin{array}{l}\text { Group } 5 \\
(n=12)\end{array}$ \\
\hline $\begin{array}{l}\text { Age (years) } \\
\text { White cell count }\left(\times 10^{9} / 1\right) \\
\text { Red cell count }\left(\times 10^{12} / 1\right) \\
\text { Haemoglobin }(g / 1) \\
\text { Platelets }\left(\times 10^{9} / 1\right) \\
\text { Lymphocytes }\left(\times 10^{9} / 1\right) \\
\text { Granulocytes }\left(\times 10^{\%} / 1\right)\end{array}$ & $\begin{array}{r}32 \cdot 3(9 \cdot 4) \\
7 \cdot 0(1 \cdot 9) \\
5 \cdot 1(0 \cdot 4) \\
152 \cdot 5(8 \cdot 6) \\
279(65) \\
2 \cdot 2(0 \cdot 7) \\
4 \cdot 4(1 \cdot 6)\end{array}$ & $\begin{aligned} 30 \cdot 5 & (10 \cdot 1) \\
6 \cdot 9 & (2 \cdot 0) \\
5 \cdot 2 & (0 \cdot 4) \\
153 \cdot 2 & (8 \cdot 7) \\
277 & (64) \\
2 \cdot 1 & (0 \cdot 6) \\
4 \cdot 4 & (1 \cdot 8)\end{aligned}$ & $\begin{array}{r}33 \cdot 1(9 \cdot 3) \\
6 \cdot 4(1 \cdot 9) \\
5 \cdot 1(0 \cdot 3) \\
151 \cdot 4(8 \cdot 6) \\
270(67) \\
2 \cdot 0(0 \cdot 6) \\
4 \cdot 0(1 \cdot 6)\end{array}$ & $\begin{array}{r}32 \cdot 5(7 \cdot 1) \\
5 \cdot 4(1 \cdot 5) \\
5 \cdot 0(0 \cdot 3) \\
147 \cdot 4(9 \cdot 1) \\
215(65) \\
1 \cdot 8(0 \cdot 5) \\
3 \cdot 1(1 \cdot 1)\end{array}$ & $\begin{aligned} 37 \cdot 6(9 \cdot 8) \\
4 \cdot 1(1 \cdot 6) \\
4 \cdot 0(0 \cdot 8) \\
117 \cdot 0(24 \cdot 0) \\
202(88) \\
1 \cdot 1(0 \cdot 7) \\
2 \cdot 3(0 \cdot 9)\end{aligned}$ \\
\hline
\end{tabular}

Group 1 = asymptomatic homosexuals or bisexuals; group 2 = asymptomatic heterosexuals; group 3 = healthy male volunteers; group $4=$ patients with persistent generalised lymphadenopathy (PGL); group $5=$ patients with the acquired immune deficiency syndrome (AIDS). 

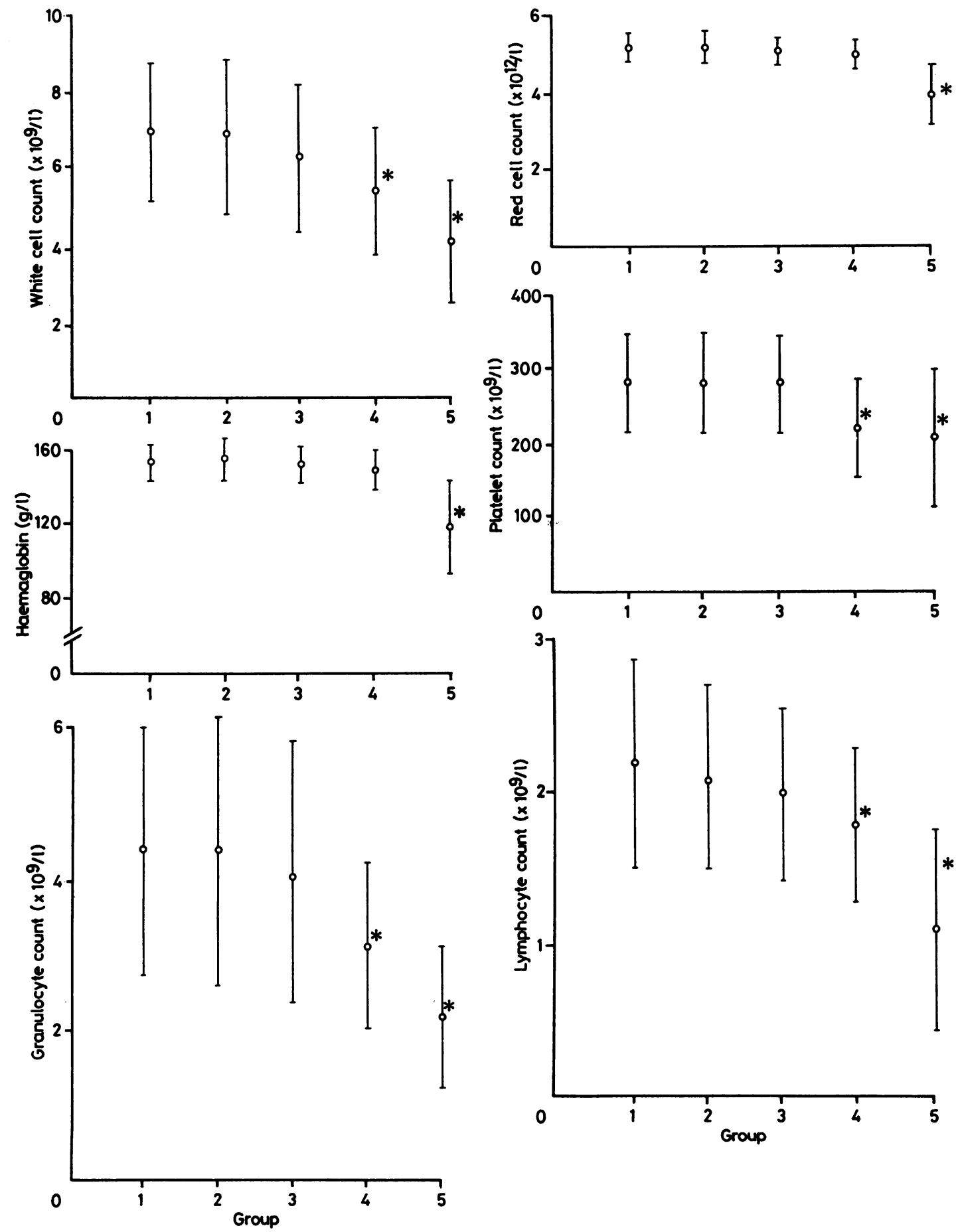

FIG 1 Mean (SD) haematological variables in each of five study groups (group 1 = asymptomatic homosexuals or bisexuals, group 2 = asymptomatic heterosexuals, group $3=$ healthy male volunteers, group $4=$ men with persistent generalised lymphadenopathy (PGL), group $5=$ men with acquired immune deficiency syndrome (AIDS)). 
asymptomatic homosexuals (group 1) showed no more monocytosis or eosinophilia than the heterosexuals or the controls. The patients with AIDS (group 5) had pronounced neutropenia, eosinopenia, and monocytopenia in addition to lymphopenia, thrombocytopenia, and anaemia.

TABLE III Distribution of atypical lymphocytes by group

\begin{tabular}{llllll}
\hline & & \multicolumn{3}{c}{ Degree of abnormality: } & \\
\cline { 3 - 5 } Group & Nosults & Mild & Moderate & Strong & $\begin{array}{l}\text { Results } \\
\text { unknown }\end{array}$ \\
\hline $1(\mathrm{n}=168)$ & 135 & 16 & 14 & 2 & 1 \\
$2(\mathrm{n}=219)$ & 177 & 21 & 18 & 3 & 0 \\
$3(\mathrm{n}=75)$ & 75 & 0 & 0 & 0 & 0 \\
$4(\mathrm{n}=41)$ & 27 & 3 & 8 & 3 & 0 \\
$5(\mathrm{n}=12)$ & 3 & 3 & 3 & 1 & 2 \\
\hline
\end{tabular}

For definition of groups see table II.

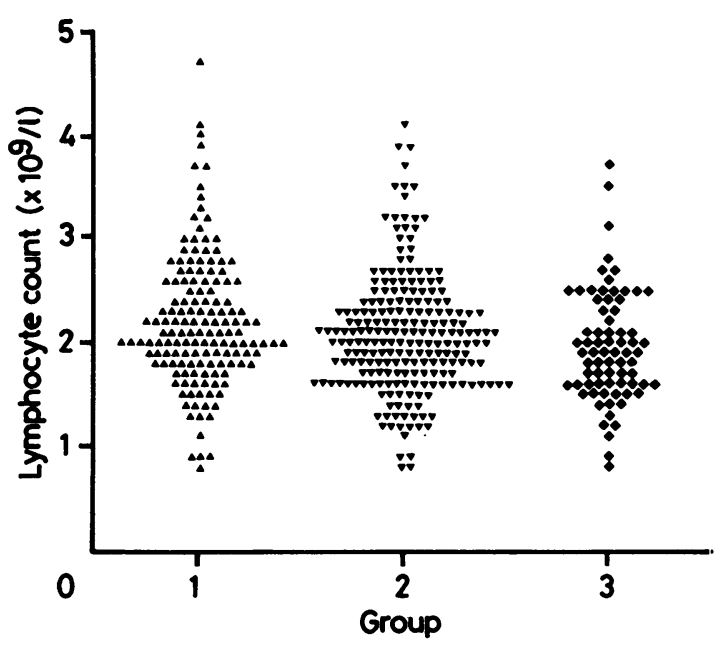

FIG 2 Total lymphocyte counts counted manually in each of the three asymptomatic groups, 1, 2, and 3 (group 1 = asymptomatic homosexuals or bisexuals attending STD clinic, group 2 = asymptomatic heterosexuals attending STD clinic, group $3=$ healthy volunteers).

\section{Discussion}

Recent research has shown that the human $T$ lymphotropic virus type III (HTLV-III), or the lymphadenopathy associated virus (LAV) retrovirus is present in most patients with AIDS and those with PGL.9-11 This virus is most probably the causative agent of AIDS. Many asymptomatic patients, however, are seropositive to HTLV-III/LAV, indicating prior exposure to and infection with this agent, and still remain well for considerable periods of time. ${ }^{12}$ A screening test for this group, which would indicate the development of an immune deficit at an early stage and hence the possible risk of AIDS developing, would be desirable. This may possibly be achieved by following up the lymphocyte count in peripheral blood.

The use of $T$ lymphocyte subsets to show AIDS related cellular immune dysfunction is too nonspecific for a screening test, and severe depression in numbers of $T$ helpers may be seen in other acute infections. ${ }^{4}$ Before the identification of the AIDS virus, screening was attempted using acid labile interferon, ${ }^{13} \quad \beta-2$ microglobulin, ${ }^{4}$ and lymphocyte proliferation and functional testing, ${ }^{4}$ yet all were found to lack the necessary specificity for screening.

The prospective study reported here attempts to define the use of a full blood count with machine differential in a population at risk of contracting AIDS, by comparison with patients with AIDS and those with PGL. We have shown clearly that there was no significant difference in any haematological variable between homosexual and heterosexual men at the $0 \cdot 1 \%$ level (fig 1). Homosexual men lacking the symptoms or signs of AIDS, such as lymphadenopathy, oral candidiasis, night sweats, unexplained fevers, weight loss, or persistent diarrhoea were therefore haematologically indistinguishable from controls (healthy volunteers and heterosexual clinic attenders) matched for age. The plotted distribution of the lymphocyte counts of homosexual men confirmed the statistical results that lymphopenia occurred no more often in that group than in the controls (fig 7). This observation is important and emphasises the need for clinicians to rely on clinical examination and judgement, rather than expecting laboratory results to provide a clear cut answer in this matter.

Two conclusions may be drawn from these data. The first is that a sexually active homosexual lifestyle with frequent sexually transmitted diseases is not in itself a cause of haematological abnormality. The second is that, in the absence of signs or symptoms of PGL or AIDS, the isolated finding of lymphopenia in a homosexual man is likely to be part of a normal distribution and not necessarily associated with AIDS. This statistical interpretation, however, does not assist in the categorisation of individual patients with lymphopenia. Other STD, notably primary herpes simplex infection and secondary syphilis, may also give rise to lymphopenia in this group. ${ }^{15}$ Pinching et al reported a high incidence $(33 \%)$ of lymphopenia in a group of volunteer homosexual men at this clinic. ${ }^{14}$ The methodology of the study reported here, however, was sufficiently different to preclude direct comparison, and none of the patients in the study by Pinching et al had active infection.

The mean (SD) platelet count in the homosexuals was $279(65) \times 10^{9} / 1$, which was statistically identical to that of the heterosexuals $\left(277(64) \times 10^{9} / 1\right)$. The group with PGL, however, had a considerably lower platelet count $\left(215(65) \times 10^{9} / 1\right)$. Our longitudinal 
study of patients with PGL showed that $10 \%$ of patients with HTLV-III seropositive lymphadenopathy had a reduction of platelet count below 1 standard deviation. This reduction is often transient, with counts returning to the normal range within weeks. Patients in the early prodrome to AIDS have also been observed to have "dips" in the platelet count, which returns to normal before the onset of opportunist infection or Kaposi's sarcoma. Several patients, however, have permanent thrombocytopenia, which results in purpura in extreme cases. These platelet abnormalities were not seen in our HTLV-III seronegative group of homosexual men and have been found in only one HTLV-III seropositive asymptomatic patient.

Homosexual men in New York have been reported as having an increased incidence of thrombocytopenic purpura. The mechanism of this platelet reduction has since been shown to be caused by the non-specific deposition of complement and immune complexes on platelets. ${ }^{15} 16$ This differs from the classic form of idiopathic thrombocytopenic purpura, which involves antiplatelet IgG. It is possible to hypothesise that the immune complex is derived from the HTLV-III virus and IgG antibody, and the transient dips in circulating platelet numbers may be caused by periods of viraemia. Further studies of the pathogenesis of thrombocytopenia, and of the clinical importance of this observation in the natural history of PGL, are under way. Despite the association between thrombocytopenia and HTLV-III infection, however, screening for this factor does not select an at risk population from asymptomatic subjects, and there was no excess of thrombocytopenia in our asymptomatic homosexuals (group 1).

The study of the manually read differential leucocyte counts has shown the extent of the cytopenia, other than lymphopenia, in patients with AIDS. Those with opportunist infection or widespread disseminated Kaposi's sarcoma had pancytopenia, with an appreciable decrease in peripheral blood neutrophils, eosinophils, monocytes, platelets, and red blood cells, as well as lymphocytes. Examinations of bone marrow from six patients showed adequate numbers of myeloid, erythroid, and megakaryocyte elements, and ZiehlNeelson stained cultures for acid fast bacilli gave negative results. Abrams et al have suggested that this finding represents increased peripheral destruction of all blood elements. ${ }^{17}$

The full blood count is therefore a useful discriminator of AIDS related problems and of progress only when signs or symptoms of AIDS or prodromal conditions are present. There is no substitute for clinical evaluation of patients at risk, and this is unlikely to change in the near future. The full blood count with differential will not screen out an at risk population from a random sample of patients. It remains possible, however, that serial estimations of total peripheral blood lymphocytes and of platelets will be of value in following up patients infected with HTLV-III.

We thank Dr Anthony Pinching for his constructive revision of the paper, Dr Don Jeffries for the virological studies, and the staff of the department of haematology and the Praed Street Clinic for all their hard work.

\section{References}

1. Gottlieb MS, Schroff R, Schanker HM, et al. Pneumocystis pneumonia and mucosal candidiasis in previously healthy homosexual men: evidence of a new acquired immunodeficiency. N Engl J Med 1981;305:1425-31.

2. Masur H, Michaelis MA, Greene JB, et al. An outbreak of community acquired Pneumocystis carinii pneumonia: initial manifestation of cellular immune dysfunction. $N$ Engl $J$ Med 1981;305: 1431-8.

3. Seigel FP, Lopez C, Hammer GS, et al. Severe acquired immuno-deficiency in male homosexuals, manifested by chronic perianal ulceration. $N$ Engl J Med 1981;305:1439-44.

4. Seligmann M, Chess L, Fahey JL, et al. AIDS-an immunological re-evaluation. $N$ Engl J Med 1984;311:1288-92.

5. Weber JN, Carmichael D, Sawyer N, et al. Clinical aspects of the acquired immune deficiency syndrome in the United Kingdom. British Journal of Venereal Diseases 1984;60:253-7.

6. Schroff RW, Gottleib MS, Prince HE, Chan LL, Fahey JL. Immunological studies of homosexual men with immunodeficiency and Kaposi's sarcoma. Clin Immunol Immunopathol 1983;27:300-4.

7. Centres for Disease Control. Persistent generalised lymphadenopathy amongst homosexual men. $M M W R$ 1982;31: 249-51.

8. Harris JRW, Weber JN. The acquired immune deficiency syndrome. In: Ferguson A, ed. Advanced medicine. Vol 20. London: Pitman Publishing Ltd, 1984.

9. Popovic M, Sarngadharan MG, Read E, et al. Detection, isolation and continuous production of cytopathic retroviruses (HTLV-III) from patients with AIDS and pre-AIDS. Science 1984; 224:497-500

10. Barré-Sinoussi F, Chermann JC, Rey F, et al. Isolation of a T-lymphotropic retrovirus from a patient at risk from the acquired immune deficiency syndrome (AIDS). Science 1983; 220:868-71.

11. Sarngadharan MG, Popovic M, Bruch L, Schupach J, Gallo RC. Antibodies reactive with human T-lymphotropic retroviruses (HTLV-III) in the serum of patients with AIDS. Science $1984 ; 224: 506-8$.

12. Cheinsong-Popov R, Weiss RA, Dalgleish A, et al. Prevalence of antibody to human T-lymphotropic virus type III in AIDS and AIDS-risk patients in Britain. Lancet 1984;ii:477-83.

13. Eyster ME, Goedert JJ, Poon M, Preble OT. Acid-labile inferferon. A possible preclinical marker for the acquired immunodeficiency syndrome. $N$ Engl J Med 1983;309:583-6.

14. Pinching AJ, McManus TM, Jeffries DJ, et al. Studies of cellular immunity in male homosexuals in London. Lancet 1983; ii: 126-9.

15. Morris L, Distenfeld A, Amorosi E, Karpatkin S. Autoimmune thrombocytopenic purpura in homosexual men. Ann Intern Med 1982;96:714-7.

16. Walsh CM, Nardi MA, Karpatkin S. On the mechanism of thrombocytopenic purpura in sexually active homosexual men. N Engl J Med 1984;311:635-9.

17. Abrams DI, Chinn EK, Lewis BJ, et al. Haematologic manifestations in homosexual men with Kaposi's sarcoma. Am J Clin Pathol 1984;81:13-8. 